\title{
THE COMPETITIVE ADVANTAGE OF SPA SERVICES IN ROMANIA
}

\author{
Rozalia Isidor ${ }^{1 *}$, Elza Kren ${ }^{2}$ \\ ${ }^{1}$ Bucharest University of Economic Studies, Romania, isidorrozalia16@stud.ase.ro \\ ${ }^{2}$ Bucharest University of Economic Studies, Romania,), krenhenriette16@stud.ase.ro
}

\begin{abstract}
This paper aims at studying Spa services in Romania, how they differ from other relaxation services offered on the market and how they can gain advantage over the competition. Is focusing on a segment of active, wellnessconscious clients who follow a healthy diet, take care of both their physical and mental health and are aware of the benefits of a visit to a Spa. Attracting such educated and demanding clients who have above-average incomes and actively promoting quality Spa services would maintain the competitive advantage of Spas over other forms of relaxation on the market. The methodology used for this analysis is the quantitative research method and the research technique is the survey. The results indicate that $86 \%$ of the people who responded to the questionnaire noted that they felt better overall after their visit to a Spa. The results obtained are in line with the issues analysed in the specialized literature.
\end{abstract}

Keywords:

Spa, relaxation, wellness, differentiation, concentration

JEL Classification: Q26, Z31, Z32

DOI: $10.24818 / \mathrm{CTS} / 3 / 2021 / 2.08$

\section{Introduction}

The people of the third millennium live and work under stressful conditions. People are therefore concerned about their wellness, looking for different ways to relax. These ways vary, encompassing a wide range of activities, which can be performed by themselves at no cost or can be purchased, starting from incredibly low prices and reaching even prohibitive ones. The aim of the study is to present and demonstrate how Spa Centers in Romania can gain and maintain their competitive advantage over other forms of relaxation on the market.

The three issues investigated are:

- The use of the information obtained by the Spa Centers from their clients to differentiate themselves and have a competitive advantage over other forms of tourism or other relaxation methods available/offered on the market;

- The degree of experience of the therapists and the quality of their services, which can be a form of competitive advantage for the Spa Centers;

- The focus on the market segment of people concerned about their wellness, and whether this is an appropriate strategy to be used by the Spa Centers in Romania. This competitive advantage of Spa Centers over other relaxation methods on the Romanian market and the focus on a specific consumer segment are part of the strategies proposed by Michael Porter, Professor of Management at Harvard Business School (Țuclea, 2003).

In our research we focused on Spa Centers and on the services they offer, which operate within the framework of Spa tourism, as part of wellness, tourism, namely places where people can go to relax and improve their wellness. We did not consider those balneary Centers where meditation or yoga are practised, nor the balneary Centers that offer secondary prophylactic treatments, therapeutic balneary treatments or medical recovery treatments and which are part of medical tourism. All these forms of

\footnotetext{
* contact author
} 
tourism, both those analysed and those mentioned, but not covered by this research, fall under the umbrella of health tourism.

The services offered in Spa Centers are aimed at all age groups, and the authors of this article do not necessarily agree with those who claim that only older people go to Spa Centers for treatment. This aspect was specific to communist society, a period in which mass tourism was practised and which is no longer relevant, with the evolution of Romanian society, the increase in the level of information available to clients and the fact that they are increasingly demanding. Spa Centers, therefore, need to find ways of differentiating themselves from other forms of relaxation that can be accessed by consumers on the market and to focus on that niche of clients interested in the procedures offered by therapists. This segment of clients is unfortunately growing due to stressful working and living conditions, on the one hand, and on the other, to focus on the market segment of those who are constantly concerned about their general wellness and who wish to adopt a healthy lifestyle.

\section{Literature review}

The concept of wellness is relatively recent and was developed by Dr Halbert Dunn, as a combination of the words wellbeing and fitness, namely of good health condition and good physical condition. The type of consumers concerned with these aspects of their lives usually want to feel better, to look better, to slow down the effects of ageing, to reduce pain and discomfort, to reduce stress and to consume natural supplements in order to improve the quality of their lives. This concept (Stănciulescu, Diaconescu, Diaconescu, 2015) is a broader one than the Spa one and encompasses under its umbrella a holistic approach, taking into account aspects related to mind and spirit, being dedicated to therapies that maintain the overall wellness of the individual. The notion of medical tourism is slightly different, which refers to people with medical conditions who travel to areas with natural resources such as different climatic conditions, mineral and thermal waters, muds, and choke damps in order to prevent or treat certain diseases and to increase work capacity. The greater the variety of health services offered on the market, the healthier and longer-lived the population of Romania will be.

The wellness tourism has currently an upward trend, but not many centers offer nutrition advice or focus on meditation. Although the concept of Spa has existed since ancient times, and in the 18th and 19th centuries it was used by the aristocracy, now the Spa industry has become one of the most widespread leisure industries, being considered a global phenomenon (Popescu, Bădiță, Șoșea, 2014) that offers varied services, with centers widely spread all over the country. The authors support the advantage of Spa Centers over the outdated offer of internationally highly prestigious balneary centers before 1990 . The new Spa concepts need to develop continuously throughout the country and diversify their services, exceeding the expectations of all clients who seek relaxation.

Depending on the level of investment, a differentiation can be observed in the Romanian Spa Centers and services, which is reflected in their results. Over time, Spa tourism has become an important segment of international tourism, with special social and economic effects (Grecu et al., 2019). The analysis of many Spa resorts in different geographical regions of the country concluded that they differ in terms of the infrastructure available and the services offered. Investments in the necessary infrastructure, but also in human resources, will bring guaranteed long-term benefits.

Spa services have become more widespread in Romania and have surpassed those offered in the balneary centers, partly because the latter were intended for mass tourism during the communist era, but are no longer practised at the same level today (Erdeli et al., 2011). The Spa Centers are in pleasant surroundings, either in stand-alone buildings, in hotels or even on cruise ships. According to the authors mentioned, the International Spa Association admits the existence of professional services, products and packages of Spa-type products for which clients, whether tourists or locals, call according to their needs or desires. The Spa Centers offer optimal conditions for relaxation, even All Inclusive. These Spa Centers can be classified as follows: Spa Club (focusing on fitness), Day Spa (offering a day of pampering), Destination Spa (guiding clients towards choosing a new lifestyle), Hotel/Resort Spa (centers located in hotels, in some of which they can choose to serve healthy food for the body), Cruise Ship Spa (centers located on board of cruise ships, offering the same quality services and procedures in a unique environment) and others, which are not the subject of this study. The varied options for 
spending time in a Spa center give as many people as possible the opportunity to find the perfect method and place for relaxation.

The wellness desired by more and more people is reflected in the high demand for quality products and services. In the hospitality industry, apart from accommodation and meals, recreation, relaxation, and sports services are also offered. Healthy lifestyles are being adopted by more and more people all over the world, including in Romania and they are leading to certain behaviours. The managers of the Spa Centers have real challenges in managing the complexity of products and services offered by employees, especially therapists, in order to meet the demands of their clients eager to relax (Ciobanu, Luches, 2017). These managers, as well as the responsible state authorities, together with NGOs, need to intensively promote the long-term benefits of a healthy lifestyle.

Romania's potential in terms of Spa services is high and, although, there are sufficient natural resources of high quality, however, in terms of development, our country is far behind other countries. The customers are mostly the same, so new consumer segments need to be attracted. An analysis carried out between 2003 and 2013 showed that the number of places in this tourism sector decreased but recovered slightly after the 2010 crisis. The Spa Centers need to be modernised, as they are considered rudimentary compared to others in Europe and not adapted to the current demand (Negrea, Cosma, Popescu, 2016). The investment is at the core of any economic sector that wants to progress, and this is also true for the Spa Centers.

In view of the above, the contribution of the Spa tourism to the development of local economies was substantial (Drăghici et al., 2014) between 2000 and 2012. According to the information provided by the National Classification of Economic Activities (NACE), during that period the total number of Spa companies increased at national level, as well as the profit they made and the number of their employees. The development of this sector is a chain reaction to the development of other activity fields in the country. We believe that entrepreneurs who add value to the society should be encouraged and supported.

Innovation, i.e. the implementation of improved products and services in the field of services, hospitality employees and managers in the Spa industry have been analysed based on their openness to these areas. Through this analysis, the aim was to reduce the gap between the services offered by Spa Centers and the expectations of customers regarding these services (Nagy, 2013). The field of service innovation is a complex one, which focuses on exceeding customers' expectations, on adapting products and services using new technologies or new methods of organisation, and on developing in advance certain services offered to customers, who are not aware yet that they would need or want them. Without innovation and the use of new technologies, there cannot be any success in any area of the economy, including Spa services.

The ageing population and the decreasing working population in Romania and Europe are well known facts. The services offered by Spa Centers, based on the natural and human resources available, can provide help and relief in this regard, through various treatments (Aluculesei, Nistoreanu, 2016). The European Union has the highest aging rate in the world, and it is growing alarmingly, so wellness tourism is being promoted as an alternative to improve health and prevent disease. We do not agree that Spa Centers are only for the elderly, but for all age groups; we consider this mentality to be an outdated one that is a legacy of our country's communist past and of the mass tourism.

The types of Spa Centers and the benefits obtained as a result of providing services were analysed and it was observed that different segments of tourists went on holidays in order to have a better general condition, to adopt a healthy lifestyle and to recover. A strong link is observed among people's needs, their motivation to choose certain relaxation services and their satisfaction with tourism field (Voight, Brown, Howat, 2011). Thus, one can understand the different segments of travellers, can communicate better with them, and can create specific products and services that perfectly fit their desires and their needs. The escape and relaxation methods generate benefits for the relationships within families and among friends. The reasons why tourists travel are always different, with some concerned about their physical appearance and others about their emotional state.

They desire a balance between their physical appearance and their mental state and using services such as aromatic oil and oil wraps or attending various nutrition or meditation courses to relieve their 
accumulated stress. We consider these motivations of people and their desire to benefit from the services of a Spa center to be well-deserved after a lot of work or learning under stressful conditions.

\section{Methodology}

To perform the analysis, we used the quantitative research method. The research technique used was the survey. As a research tool, we created a questionnaire including 23 questions, which we asked online (on WhatsApp and Facebook Messenger), to relatives, friends and acquaintances and we received 48 responses over 2 days.

The aim of this research was to identify and analyse the competitive advantage of the Spa services in Romania. These services are generally aimed at those concerned about their physical appearance and mental health, who want to relax and have a general state of wellness, compared to other forms of relaxation available on the market. The type of competitive advantage targeted is the one obtained by applying a differentiation strategy on a niche (a specific consumer segment), a type of strategy proposed by Michael Porter. By means of the ways in which employees provide services in Spa Centers, elements of uniqueness can be acquired, which can lead to the creation of an advantage over competing companies.

One of the objectives is to identify whether Spa Centers can obtain the necessary information from their clients that will help them to have a competitive advantage over other available relaxation services offered on the market. Thus, questions were asked to find out how many people know about the services offered in Spa Centers:

$>$ whether they know that it is part of wellness tourism, which in turn, together with medical tourism, falls under the umbrella of health tourism;

$>$ if they know what the benefits of visiting a Spa center would be;

$>$ whether they have ever been to such a place and if so, how many times;

$>$ what motivated them to come and what would make those who have been to come back and what would make those who have never been to come for the first time;

$>$ what types of Spa Centers they would choose to relax in.

A second objective is to find out whether the level of experience of the therapists and the quality of their services can also be a form of competitive advantage for Spa Centers. We asked the respondents:

- if they had noticed an improvement in their general condition after a visit to a spa,

- whether the services offered by a particular therapist would lead them to return to the same spa;

- why they would choose relaxation in a Spa center over recreation and relaxation in another activity or place available on the market.

The third objective is to determine to what extent focusing on a specific niche, i.e. the segment of consumers concerned about their wellness, could be an appropriate strategy to be used by Spa Centers in Romania. In order to achieve this objective, we asked questions about:

$\circ$ how active these people consider themselves to be and how healthy their diet is;

- whether they are concerned about their physical and mental wellness and if they practice physical or mental activities (e.g. yoga, fitness, meditation, etc.);

○ whether they consider themselves to be sociable people,

- what kind of services they have chosen or would choose in a Spa visit;

o what is their preferred form of tourism;

o whether the way they relax in a Spa is an advantage over spending their leisure time in other wellness centers (excluding Spa Centers), in balneary resorts or other similar centers;

- what is their gender, their age, whether they live in urban or rural areas and if they earn an income, what range would this fall.

Table no. 1 shows the socio-demographic characteristics of the sample surveyed. 
Table no. 1: Socio-demographic characteristics of the sample surveyed

\begin{tabular}{|c|c|c|c|c|c|c|c|c|c|}
\hline \multicolumn{2}{|c|}{ Gender } & \multicolumn{2}{|c|}{ Age (years) } & \multicolumn{2}{|c|}{ Area } & \multicolumn{2}{|c|}{ Income (RON) } & \multicolumn{2}{|c|}{ Education } \\
\hline \multirow{3}{*}{$\mathrm{F}$} & \multirow{3}{*}{$75 \%$} & Below 18 & $2,1 \%$ & \multirow{3}{*}{ Urban } & \multirow{3}{*}{$\begin{array}{c}91,7 \\
\%\end{array}$} & Below 1500 & $12,5 \%$ & Primary & $6,3 \%$ \\
\hline & & $18-35$ & $37,5 \%$ & & & $1500-2500$ & $18,8 \%$ & High school & $14,6 \%$ \\
\hline & & $36-50$ & $31,3 \%$ & & & $2501-5000$ & $37,5 \%$ & Bachelorship & $52,1 \%$ \\
\hline \multirow{3}{*}{$\mathrm{M}$} & \multirow{3}{*}{$25 \%$} & $51-65$ & $22,9 \%$ & \multirow{3}{*}{ Rural } & \multirow{3}{*}{$8,3 \%$} & Over 5000 & $12,5 \%$ & Master & $25 \%$ \\
\hline & & Over 65 & $6,3 \%$ & & & $\begin{array}{l}\text { I do not } \\
\text { generate } \\
\text { income }\end{array}$ & $10,4 \%$ & $\mathrm{PhD}$ & $2,1 \%$ \\
\hline & & & & & & $\begin{array}{l}\text { I do not wish } \\
\text { to declare }\end{array}$ & $8,3 \%$ & & \\
\hline Total & $100 \%$ & & $100 \%$ & & $100 \%$ & & $100 \%$ & & $100 \%$ \\
\hline
\end{tabular}

Source: Prepared by the authors based on the research

Of the total respondents, $76 \%$ are women, of which $37,5 \%$ are between 18 and 35 years old, and $91,7 \%$ of those surveyed live in urban areas. The incomes of $37,5 \%$ of them are between 2501 and 5000 lei, and $52,1 \%$ obtained the bachelor's degree.

\section{Results and discussion}

The following results were generated by the research:

54\% of the respondents did not know which form of tourism the Spa tourism belonged to;

$>33 \%$ of the respondents considered themselves to be less active and 33\% active;

$>21 \%$ considered their diet to be appropriate and only $5 \%$ extremely healthy;

$>25 \%$ are very much concerned about their physical and mental health and $17 \%$ genuinely concerned;

$>27 \%$ of them do not practice any physical activity, $20 \%$ practice meditation, $28 \%$ fitness and $20 \%$ practice other activities;

The benefits of a visit to a Spa center were considered:

to give a general feeling of wellness $35 \%$, stress reduction/relaxation $32 \%$ (Fig. 1);

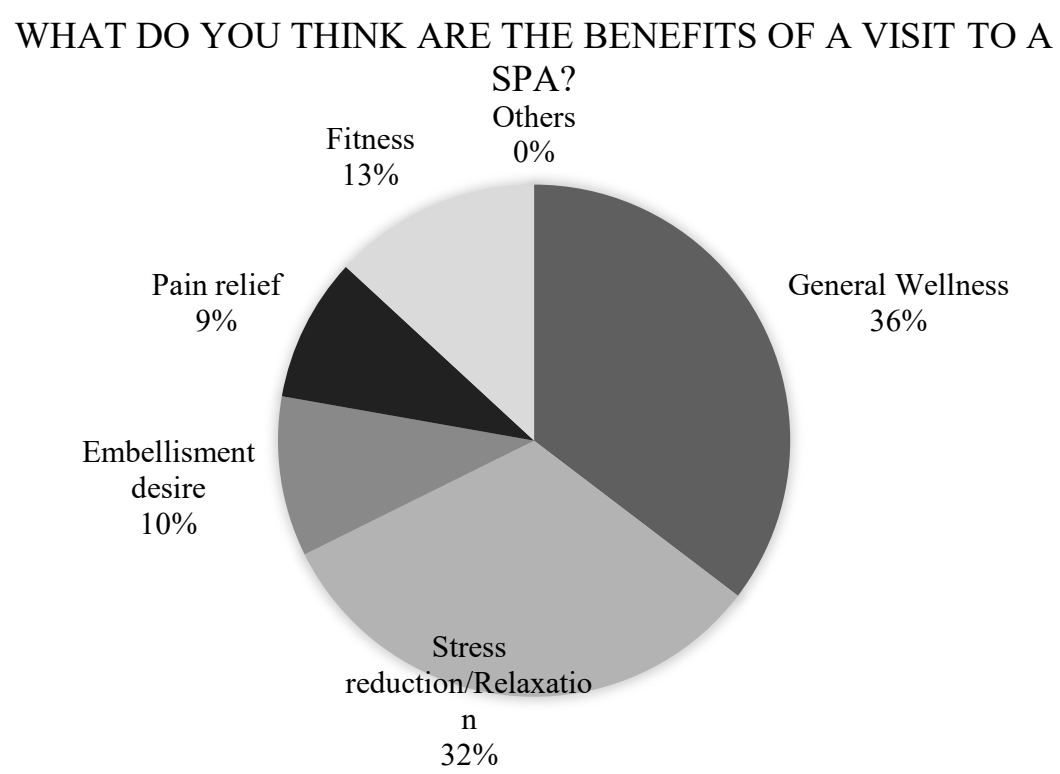

Fig. no. 1: Benefits of a visit to a Spa center

Source: Prepared by the authors based on the research 
$81 \%$ of them consider themselves as sociable people;

$>60 \%$ of the people who participated in the survey had been to a Spa center;

$>16 \%$ of those who have been to a Spa center have visited such a place between 2 and 10 times, and $28 \%$ more than 10 times;

$>$ The desire to adopt a healthy lifestyle was chosen by $20 \%$ of participants who had been to a Spa at least once; $18 \%$ were motivated by curiosity, $14 \%$ by a desire for beauty and $12 \%$ by a desire to relax because of physical pain;

$>86 \%$ noted that they felt better overall;

$>$ The answer Relaxing atmosphere, interior layout and cleanliness was chosen by $34 \%$ of respondents as the reason why they would visit or revisit a Spa center (Fig. 2);

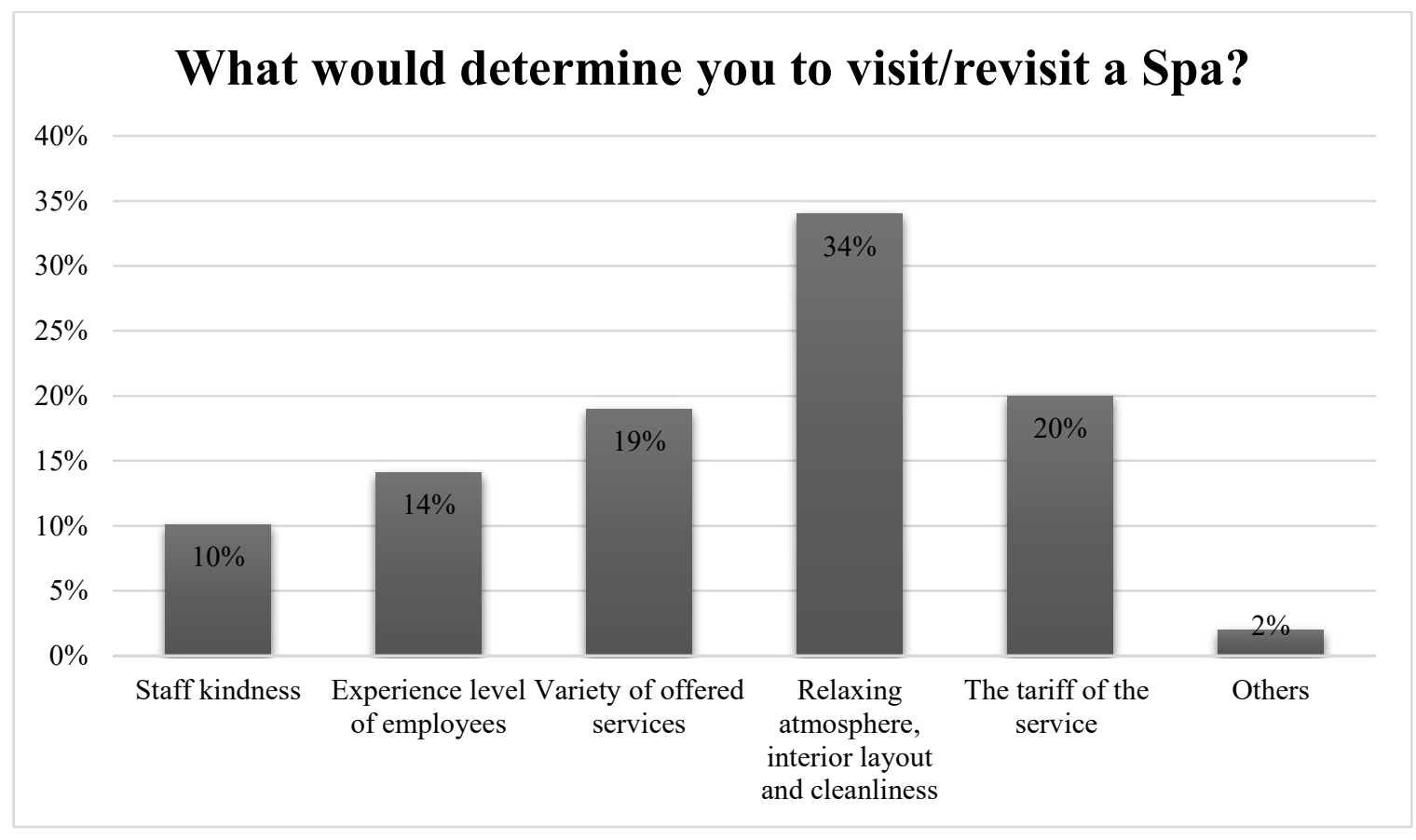

Fig. no. 2: Reason for visiting/revisiting a Spa center

Source: Prepared by the authors based on the research

Approximately $71 \%$ would return to the same Spa center, due to the services offered by a certain therapist;

When asked the open question: Why they would choose a Spa to relax over another relaxing activity? some of the answers were: because it is a healthy environment and it can influence wellness; because it relaxes them; for the wide range of services they can benefit from and have to leave to the experts; because there are many options in one place; to be pampered; for stress reduction. There were also 5 participants who would not choose this option. Three others because they had never been to a Spa center, they could not imagine this;

$>39 \%$ chose to spend a day at a Day Spa, $24 \%$ at a Hotel Spa and $17 \%$ at a Cruise Ship Spa;

$>$ Seaside tourism was preferred by $41 \%$, mountain tourism by $35 \%$ and health tourism (including Spa) by $17 \%$;

$>63 \%$ would choose spending time at a Spa center over wellness centers and balneary resorts;

$>$ The preferred services they chose or would choose were $23 \%$ massage (Fig. 3). 


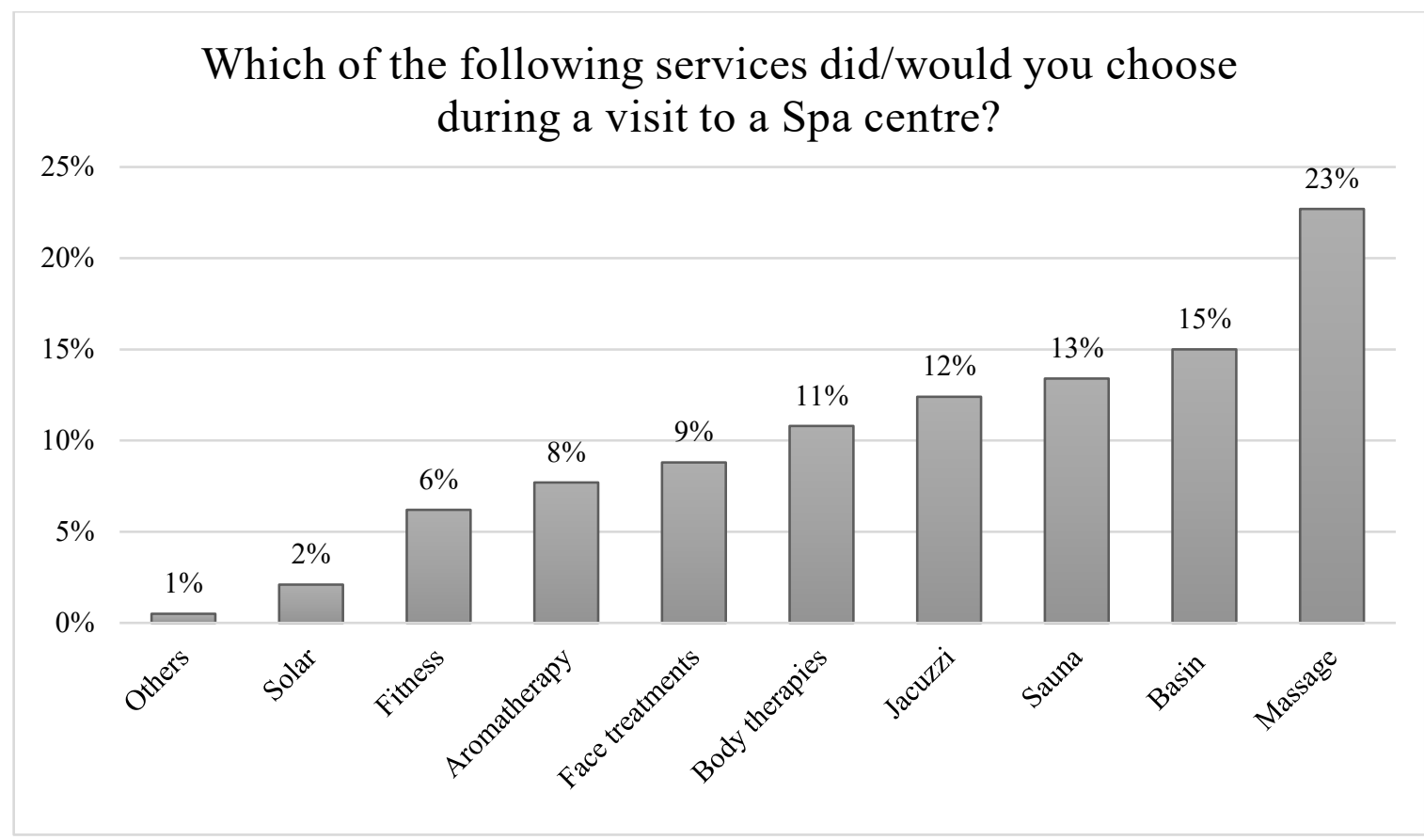

Fig. no. 3: Services chosen at a Spa center

Source: Prepared by the authors based on the research

The conclusion is that a visit to a Spa Center will reduce stress, provide a state of well-being and relaxation. Questionnaire participants have the desire to adopt a healthy lifestyle and want to visit or revisit such a place.

All data and information obtained from the participants in the survey by filling in the online questionnaire were processed by our team. The results obtained entitle us to consider that the 3 objectives mentioned at the beginning of the paper are true and in line with the issues analysed in the specialized literature.

\section{Conclusions}

Following the research carried out on how Spa Centers, through the services they offer, can benefit from competitive advantages over other forms of relaxation offered to willing people and existing on the market, we concluded that the objectives analyzed are true.

The three objectives of the paper are: 1) the use of the information obtained by the Spa Centers from their clients in order to differentiate themselves and have a competitive advantage over other forms of tourism or other relaxation methods available/offered on the market; 2) the degree of experience of the therapists and the quality of their services, which can be a form of competitive advantage for the Spa Centers; 3) the focus on the market segment of people concerned about their wellness, and whether this is an appropriate strategy to be used by the Spa Centers in Romania. As a result of the online filling in of the questionnaires by the 48 participants and of the fact that they answered the 23 questions asked over 2 days, it was found that these 3 objectives are true and that the Romanians are concerned about their wellness. They want to relax after stressful periods, when they are working or studying intensively, because of some pain they have or simply because they want to be active and keep fit. The European trend is confirmed: Spa Centers and Spa services are on the rise and differentiate themselves from other forms of relaxation available on the market, serving clients from a certain niche and have a competitive edge over them (those where yoga, meditation are practiced and the balneary ones).

If Spa Centers, through all their employees (therapists, managers, receptionists, etc.) communicate effectively with their clients, offer them quality services, treat them with respect and kindness, ask them questionnaires to assess their satisfaction, promote an active lifestyle based on a healthy diet and 
emphasize the benefits of body treatments, massages, sauna and jacuzzi sessions, aromatherapy treatments and invest in the necessary infrastructure and staff, then they will certainly differentiate themselves from the competition of other forms of relaxation offered on the market and will benefit from a competitive advantage.

The experience of the therapists acquired through the schools they have graduated from and the specialization courses they have completed, the personal development training, the learning of foreign languages will all contribute in a successful way to the competitive advantage of the Spa services.

Targeting these services at a segment of customers who are sociable, interested and concerned about their wellness and who have above-average education, high income, who like to travel and who engage in physical and mental activity, regardless of their age is a focus that can be used and will bring competitive benefits to Spa Centers.

This research could be continued in a future project, taking into account: the dynamic evolution of the Spa services in Romania; the continuous development of new technologies; the growth of the Romanian economy; the rising standard of living in the country; the crisis caused by the COVID-19 pandemic; the mobility of tourists. Therefore, the possibility of accessing new segments of international tourists, who, taking advantage of the lower level of tariffs in Romania, would like to relax and improve their wellness in the Spa Centers on the Romanian territory.

\section{References}

Aluculesei, A.C., Nistoreanu, P., 2016. Romanian Wellness Tourism - A Potential Solution with Positive Implications for the Effects of the Aging Population in the European Union. Amfiteatru Economic, 18 (Special Issue No. 10), pp. 767-780. [Online] Available at la: $<$ https://www.amfiteatrueconomic.ro/ ArticolEN.aspx?CodArticol=2567 $>$ [Accessed on January 16th, 2021].

Ciobanu, C., Luches, D., 2017. The influence of the complexity of wellness services upon different aspects of the management of wellness tourism organizations in Romania. Procedia - Social and Behavioral Sciences 238, 535 - 541. [Online] Available at: $<$ https://www.sciencedirect.com $/$ science/article/ pii/S1877042818300636> [Accessed on January 16th, 2021].

Drăghici, C. C., Pintilii, R. D., Peptenatu D., Comănescu L. G., Sirodoev I., 2014. The Role of SPA Tourism in the Development of Local Economies from Romania. Procedia Economics and Finance, Volume 23, Pages 1573-1577 [Online] Available at: $<$ https://www.sciencedirect.com $/$ science/article $/$ pii/ S2212567115004001> [Accessed on January 16th, 2021].

Erdeli, G., Dincă, A. I., Gheorghilaş, A., Surugiu, C., 2011. Romanian spa tourism: a communist paradigm in a post-communist era. Human Geographies - Journal of Studies and Research in Human Geography, 5.2, 41-56. [Online] Available at: $<$ http://www.humangeographies.org.ro/volume-5-issue-2-2011/525abstract> [Accessed on January 16th, 2021].

Grecu, A., Drăghici, C. C., Gruia, A. K., Teodorescu, C., Dima, C., 2019. Prospects for the development of spa tourism in Romania. International Scientific Conference Geobalcanica. [Online] Available at: $<$ https://www.researchgate.net/publication/335580726_PROSPECTS_FOR_THE_DEVE LOPMENT_OF_SPA_TOURISM_IN_ROMANIA> [Accessed on January 16̄th, 2021].

Nagy, A., 2013. The orientation towards innovation of spa hotel management: the case of Romanian spa industry. Procedia - Social and Behavioral Sciences, 124, 425-431. [Online] Available at: $<$ https://www.sciencedirect.com/science/article/pii/S1877042814020527> [Accessed on January 16th, 2021].

Negrea, A., Cosma, M. R., Popescu, L. M., 2016. Sustainable development of spa tourism in Romania. Quality Access to Success, 17(S1). [Online] Available at: $<$ https: $/ /$ www.researchgate.net/ publication/300050110_Sustainable_development_of_spa_tourism_in_Romania $>$ [Accessed on January 16th, 2021].

Popescu, L., Bădiţă, A., Şoșea, C., 2014. Present and perspectives for health tourism - spa services in Romania. Forum geografic. Studii si cercetări de geografie si protecţia mediului (Geographic Forum: geography and Environmental protection studies and research), Volume XIII, Issue 2 (December), pp. 242-248. [Online] Available at: $<$ https://www.researchgate.net/publication/277620187> [Accessed on January 16th, 2021]. 
Stănciulescu, G. C., Diaconescu, G. N., Diaconescu, D. M., 2015. Health, spa, wellness tourism. What is the difference? Knowledge Horizons - Economics, Volume 7, No. 3, pp. 158-161. [Online] Available at: $<$ http://www.orizonturi.ucdc.ro/arch.php $>$ [Accessed on January 15th, 2021].

Țuclea, C., 2003. Management strategic (Strategic management). Uranus Publishing House, Bucharest.

Voight, C., Brown, G., Howatt, G., 2011. Wellness tourists: in search of transformation. Tourism review. VOL. 66 NO. 1/2 2011, pp. 16-30. [Online] Available at: $<$ https://www.researchgate.net/publication/ 242023593_Wellness_tourists_In_search_of_transformation> [Accessed on January 16th, 2021]. 